\title{
LATTICE SITES AND STABILITY OF IMPLANTED Er IN FZ AND CZ Si
}

\author{
U. Wahl $^{1}$, J.G. Correia ${ }^{2}$, G. Langouche ${ }^{1}$, A. Vantomme ${ }^{1}$, and the ISOLDE collaboration ${ }^{2}$ \\ ${ }^{1}$ Instituut voor Kern- en Stralingsfysica, University of Leuven, Celestijnenlaan 200 D, \\ B-3001 Leuven, Belgium, email: ulrich.wahl@fys.kuleuven.ac.be \\ ${ }^{2}$ CERN-PPE, CH-1211 Genève 23, Switzerland
}

\begin{abstract}
We report on the lattice location of ${ }^{167} \mathrm{Er}$ in $\mathrm{Si}$ measured by conversion electron emission channeling. In both $\mathrm{FZ}$ and $\mathrm{CZ} \mathrm{Si}$, a high fraction of $\mathrm{Er}(>65 \%)$ occupies near-tetrahedral interstitial (T) sites directly following $60 \mathrm{keV}$ room temperature implantation at doses of $6 \times 10^{12} \mathrm{~cm}^{-2}$. For higher doses, the as-implanted near-T fractions of Er visible by emission channeling are smaller, due to the beginning of amorphization. Following the recovery of implantation damage at $600^{\circ} \mathrm{C}$, more than $70 \%$ of Er is found on near-T sites in both FZ and CZ Si. In FZ Si, Er exhibits a remarkable thermal stability and only prolonged annealing for several hours reduces the near- $\mathrm{T}$ fraction. On the other hand, annealing of $\mathrm{CZ} \mathrm{Si}$ at $900^{\circ} \mathrm{C}$ for more than 10 minutes results in the majority of Er probes in sites of very low symmetry or disordered surroundings.
\end{abstract}

\section{INTRODUCTION}

During recent years the understanding of the structural properties of $\mathrm{Er}$ in $\mathrm{Si}$ has been gradually increasing. Theory has investigated isolated tetrahedral interstitial $(\mathrm{T})$ and substitutional (S) Er in various charge states $(0,1+, 2+, 3+)[1,2]$, and hexagonal interstitial $(\mathrm{H}) \operatorname{Er}[1]$. From both of these studies, it was concluded that the $\mathrm{T}$ site should be the most stable position for isolated $\mathrm{Er}$ in any charge state. While from the theoretical point of view it is easiest to consider isolated Er, it is not straightforward to observe it in the experiment. The cleanest way to produce Er-doped Si samples with low concentrations of C, N and O is ion implantation of float zone (FZ) or MBE Si [3,4]. A drawback of the implantation studies is of course the significant radiation damage or, at higher doses, amorphization of the Si host. Most experimental techniques such as photoluminescence (PL) or deep level transient spectroscopy (DLTS) require near-complete removal of this damage. This creates new problems since the temperatures required for the annealing of Er-implanted Si $\left(600-900^{\circ} \mathrm{C}\right)$ favour Er clustering or, at concentrations above $10^{18}$ $\mathrm{cm}^{-3}$, precipitation [5,6]. It is believed that the cubic Er center which dominates the PL of Erimplanted $\mathrm{FZ} \mathrm{Si}$ is due to isolated $\mathrm{Er}$ on $\mathrm{T}$ sites [7]. When working with very low $\mathrm{Er}$ concentrations, even the small amount of O present in FZ Si can significantly modify the electrical properties of Er [4].

On the other hand, the Er-O interaction is beneficial because it significantly increases the luminescence efficiency. It seems now generally accepted that this is, at least partly, related to the formation of complexes between $\mathrm{Er}$ and multiple $\mathrm{O}$ atoms $[4,6,8,9]$. While, to our knowledge, no theoretical work has been published so far on the microscopic structure of Er-O complexes in $\mathrm{Si}$, the formation of $\mathrm{Er}_{2} \mathrm{O}_{3}$-like centers was clearly observed in extended X-ray absorption fine structure (EXAFS) experiments $[10,11]$ on Er-implanted Czochralski (CZ) Si annealed to $900^{\circ} \mathrm{C}$. The PL spectrum of Er and O co-doped samples is usually dominated by Er-related centers having non-cubic symmetry [7] and the PL intensity of these centers is correlated with the O/Er ratio rather than the concentration of Er and $\mathrm{O}[12]$. 
Recently, we reported on direct lattice location experiments of ${ }^{167} \mathrm{Er}$ using the emission channeling technique [13-15]. This experimental method makes use of the fact that charged particles emitted from radioactive isotopes in a single crystal experience channeling or blocking effects along crystallographic axes and planes. This leads to an anisotropic emission yield from the crystal surface, which depends in a characteristic way on the occupied lattice sites of the probe atoms. Following implantation of ${ }^{167} \mathrm{Tm}\left(\mathrm{t}_{1 / 2}=9.25 \mathrm{~d}\right)$ with doses around $5-6 \times 10^{13} \mathrm{~cm}^{-2}$, we found that the majority of the decay product ${ }^{167 \mathrm{~m}} \mathrm{Er}(2.27 \mathrm{~s})$ occupies near-T sites in both FZ and CZ Si after annealing at $600^{\circ} \mathrm{C}$ [13]. While in $\mathrm{FZ} \mathrm{Si}{ }^{167 \mathrm{~m}} \mathrm{Er}$ was stable on near- $\mathrm{T}$ sites at $900^{\circ} \mathrm{C}$ [14], annealing $\mathrm{CZ} \mathrm{Si}$ at this temperature considerably reduced the near-T Er fraction.

In this contribution we first focus on the Er lattice location results from samples implanted with much lower doses $\left(6 \times 10^{12} \mathrm{~cm}^{-2}\right.$ at $\left.60 \mathrm{keV}\right)$. In the as-implanted state these experiments characterize the lattice sites of isolated Er, though in an environment which is still rich in defects resulting from the implantation process. Secondly, we report in detail on the ${ }^{167 \mathrm{~m}} \mathrm{Er}$ emission channeling from both $\mathrm{FZ}$ and $\mathrm{CZ}$ Si following isothermal annealing at $900^{\circ} \mathrm{C}$. While in this case the thermal processing always affects a mixture of $\mathrm{Tm}$ and $\mathrm{Er}$, and lattice location of $\mathrm{Er}$ is done following the decay of ${ }^{167} \mathrm{Tm}$ to ${ }^{167 \mathrm{~m}} \mathrm{Er}$, the chemical similarity of both rare earth elements should allow us to draw conclusions on the behaviour of $\mathrm{Er}$ in $\mathrm{Si}$.

\section{EXPERIMENT}

The angular-dependent emission yield of conversion electrons following the decay of ${ }^{167} \mathrm{Tm}$ to ${ }^{167} \mathrm{Er}$ was measured by position-sensitive Si pad detectors [17]. Detailed descriptions of this detection method and the experimental setup are to be found in Refs. [13-16]. Si samples implanted with $60 \mathrm{keV}^{167} \mathrm{Tm}$ at room temperature were produced at the ISOLDE facility at CERN. The characteristics of the investigated samples are listed in Table I. All of the samples were dipped in HF prior to implantation in order to remove native oxide layers. Two types of thermal processing were applied, either $e x$-situ vacuum annealing $\left(<10^{-5} \mathrm{mbar}\right)$ in a furnace, or in-situ annealing at $<10^{-6}$ mbar in the channeling goniometer which is equipped with a $\mathrm{W}$ filament for radiative heating of the sample holder. Some comments are appropriate on these methods of annealing. In the case of the furnace the temperature was measured outside of the quartz tube containing the sample by means of a Chromel/Alumel thermocouple, and the annealing time is speci-

\begin{tabular}{|c|c|c|c|c|c|c|}
\hline \multicolumn{7}{|c|}{ Table I: Characteristics of the 10 samples investigated } \\
\hline Sample \# & Type & $\begin{array}{c}\text { Resistivity } \\
{[\Omega \mathrm{cm}]}\end{array}$ & Surface & $\begin{array}{c}\text { Tm+Er dose } \\
{\left[\mathrm{cm}^{-2}\right]}\end{array}$ & $\begin{array}{c}\text { Max. Tm+Er } \\
\text { concentration }\left[\mathrm{cm}^{-3}\right]\end{array}$ & $\begin{array}{c}\text { Type of } \\
\text { annealing }\end{array}$ \\
\hline FZ 1 & $p$ & $10 \mathrm{k}$ & $<111>$ & $5.6 \times 10^{12}$ & $2.7 \times 10^{18}$ & $\begin{array}{c}\text { in-situ + } \\
\text { furnace }\end{array}$ \\
FZ 2 & $p$ & $10 \mathrm{k}$ & $<111>$ & $4.0 \times 10^{13}$ & $1.9 \times 10^{19}$ & furnace \\
FZ 3 & $p$ & $10 \mathrm{k}$ & $<111>$ & $4.8 \times 10^{13}$ & $2.3 \times 10^{19}$ & in-situ \\
FZ 4 & $n$ & $>4 \mathrm{k}$ & $<111>$ & $5.1 \times 10^{13}$ & $2.4 \times 10^{19}$ & in-situ \\
CZ 1 & $n$ & $3-12$ & $<111>$ & $5.8 \times 10^{12}$ & $2.8 \times 10^{18}$ & in-situ \\
CZ 2 & $n$ & $1-10$ & $<100>$ & $1.1 \times 10^{13}$ & $5.3 \times 10^{18}$ & in-situ \\
CZ 3 & $n$ & $1-10$ & $<100>$ & $2.0 \times 10^{13}$ & $9.6 \times 10^{18}$ & furnace \\
CZ 4 & $n$ & $1-10$ & $<100>$ & $3.5 \times 10^{13}$ & $1.7 \times 10^{19}$ & furnace \\
CZ 5 & $p$ & $5-14$ & $<100>$ & $4.4 \times 10^{13}$ & $2.1 \times 10^{19}$ & in-situ \\
CZ 6 & $n$ & $1-10$ & $<100>$ & $4.8 \times 10^{13}$ & $2.3 \times 10^{19}$ & furnace \\
\hline
\end{tabular}




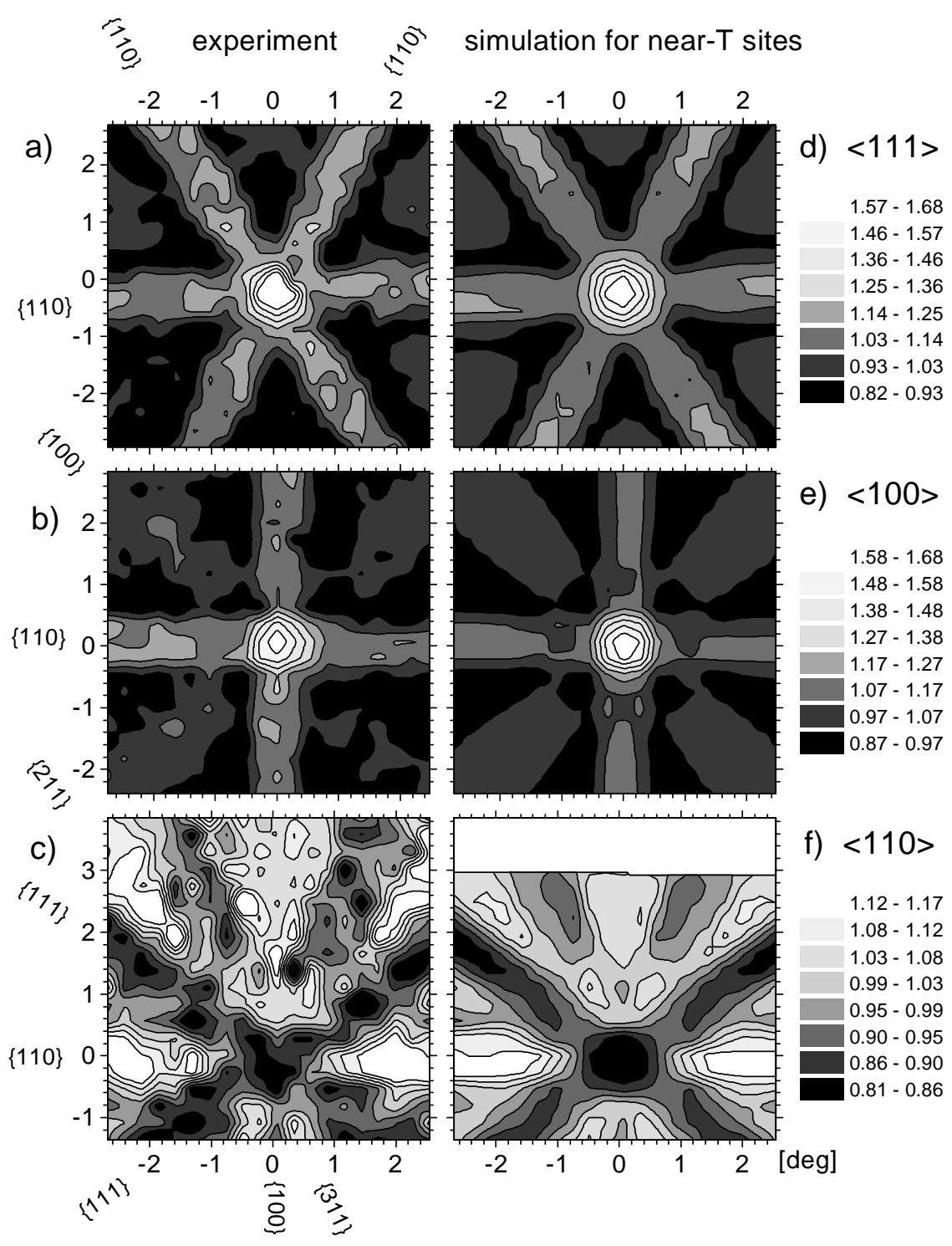

Fig. 1: (a),(b),(c): channeling patterns from ${ }^{167 \mathrm{~m}} \mathrm{Er}\left(\mathrm{t}_{1 / 2}=2.28 \mathrm{~s}\right)$ following room temperature implantation of ${ }^{167} \mathrm{Tm}$ into $\mathrm{FZ} \mathrm{Si}$, sample 1. Shown are the normalized electron emission yields from the combined intensity of 150,198 and $206 \mathrm{keV}$ electrons around $\langle 111\rangle,\langle 100\rangle$ and $\langle 110\rangle$ directions. (d),(e),(f): best fits of simulated patterns to the experimental yields, corresponding to $68 \%, 65 \%$ and $59 \%$ of emitter atoms on sites which are displaced by $0.42 \AA$ from the $\mathrm{T}$ site. fied as the time between introducing the tube into the furnace and removing it again. While the temperature measurement is quite accurate in this case due to the small temperature gradient in the large furnace, it takes 1-2 min before thermal equilibrium is established and the sample has actually reached this temperature. In case of the insitu annealing in the goniometer, temperature is measured by two thermocouples attached to the sample holder close to the sample, and the annealing time given is the time after reaching the setpoint temperature. In this case, however, the temperature uncertainty amounts to $\pm 10-15^{\circ} \mathrm{C}$ due to the temperature gradients between thermocouples, sample holder and sample surface.

\section{RESULTS AND DISCUSSION}

Figures 1(a), 1(b) and 1(c) show the normalized emission yield of conversion electrons from ${ }^{167 \mathrm{~m}} \mathrm{Er}$ around the $\langle 111\rangle,\langle 100\rangle$ and $\langle 110\rangle$ directions of sample FZ 1, measured as-implanted with a dose of $5.6 \times 10^{12} \mathrm{~cm}^{-2}{ }^{167} \mathrm{Tm}$. The prominent channeling effects along axial $\langle 100\rangle$ and $<111>$ and planar $\{110\}$ directions, less pronounced channeling effects along $\{100\}$ and $\{211\}$, and yield minima along axial $\langle 110\rangle$ and planar $\{111\}$ and $\{311\}$ directions provide direct evidence that the majority of ${ }^{167 \mathrm{~m}} \mathrm{Er}$ occupies sites close to the tetrahedral interstitial (T) position. A 


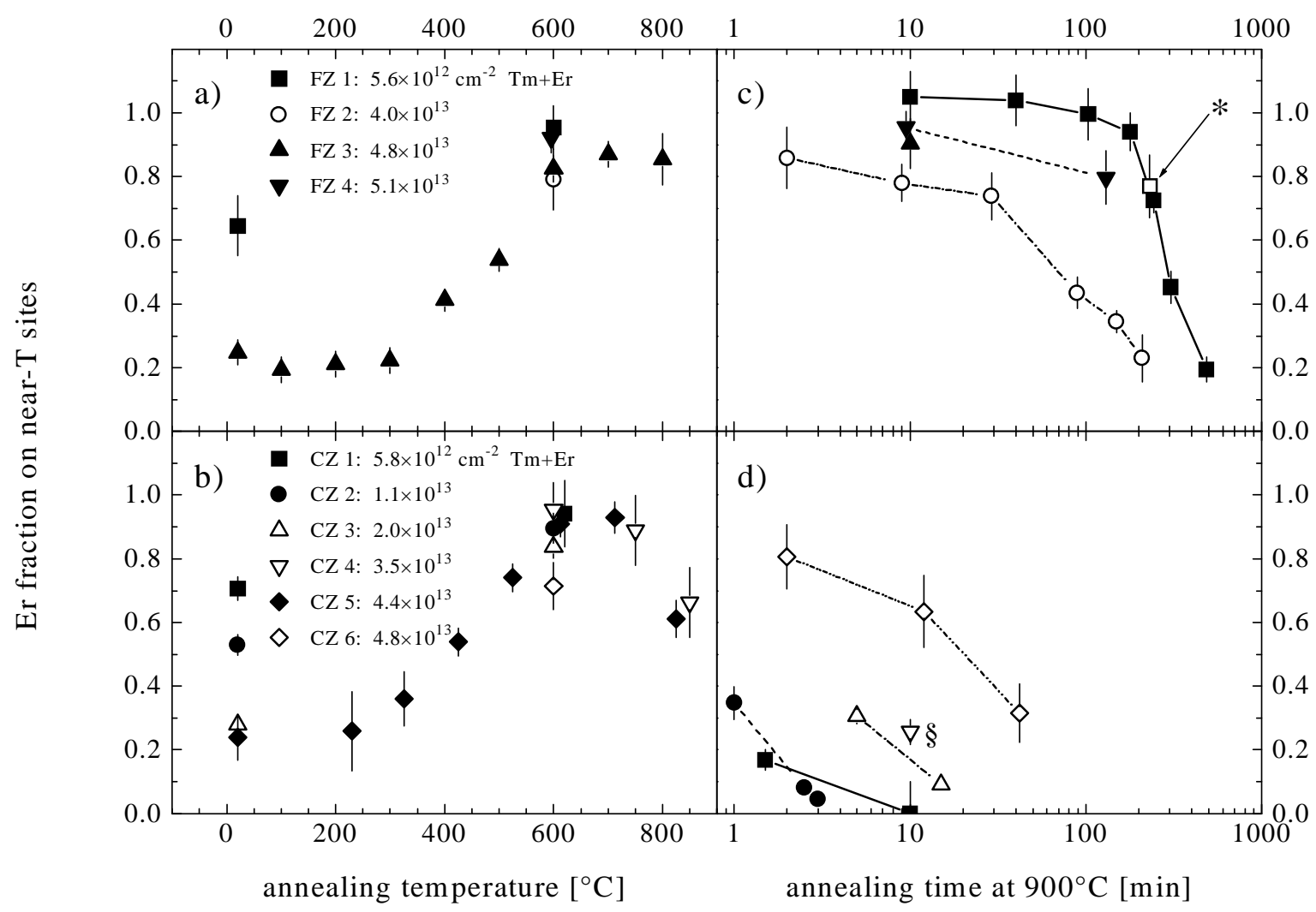

Fig. 2: Fractions of ${ }^{167 \mathrm{~m}} \mathrm{Er}$ on near-T sites obtained during isochronal annealing sequences (10 min, measurements at $20^{\circ} \mathrm{C}$ ) for $\mathrm{FZ} \mathrm{(a)} \mathrm{and} \mathrm{CZ} \mathrm{Si} \mathrm{samples} \mathrm{(b),} \mathrm{and} \mathrm{isothermal} \mathrm{annealing} \mathrm{sequences} \mathrm{at} 900^{\circ} \mathrm{C}$ for $\mathrm{FZ}$ (c) and $\mathrm{CZ} \mathrm{Si} \mathrm{samples} \mathrm{(d).} \mathrm{Filled} \mathrm{symbols} \mathrm{correspond} \mathrm{to} \mathrm{crystals} \mathrm{annealed} \mathrm{in-situ} \mathrm{in} \mathrm{the} \mathrm{channeling}$ goniometer, while open symbols indicate furnace-annealed samples. Exceptions are the data point for sample FZ 1 indicated by *, which was furnace-annealed, and the one for sample CZ 4 indicated by $\S$, which was annealed at $950^{\circ} \mathrm{C}$ instead of $900^{\circ} \mathrm{C}$.

quantitative analysis of these emission patterns is achieved by comparing them to the results of electron channeling simulations from emitter atoms occupying different lattice sites. The corresponding simulation parameters and fitting routines have already been described in more detail in previous papers [13-16]. The best fit results, allowing for only one Er lattice site besides random sites, are shown in Figs. 1(d), 1(e) and 1(f). They correspond to 68\%, 65\% and 59\% of Er emitter atoms which are displaced by $0.42 \AA$ from the $\mathrm{T}$ site. As already remarked before [13-16], the displacement of $0.42 \AA$ can also be interpreted as a mixture of several sites in the range 0 to $\approx 0.6 \AA$ from the $\mathrm{T}$ sites. Introducing other sites, however, did not significantly improve the fit quality. Including also our previous results, we therefore conclude that in the as-implanted state in FZ Si, Er prefers the same lattice sites as it does during and after annealing at $900^{\circ} \mathrm{C}$.

Figures 2(a) and 2(b) show the fractions of ${ }^{167 \mathrm{~m}} \mathrm{Er}$ on the near-T sites derived from the emission channeling data for all 10 investigated samples following isochronal annealing sequences (10 min) up to $900^{\circ} \mathrm{C}$. For the as-implanted state the fraction on the near-T sites decreases with increasing dose of implanted ${ }^{167} \mathrm{Tm}$. This behaviour is due to the increase in damage when going from lower to higher doses, as individual damage cascades overlap and amorphization begins. The growing damage has two different effects on the channeling effect. First, probe atoms tend to occupy sites which are of low crystal symmetry and further away from high-symmetry sites. This 
usually shows up as a narrowing of channeling profiles. Secondly, displaced lattice atoms are responsible for dechanneling of electrons on their way towards the surface, which intensifies the isotropic emission yield and typically shows up as an increase in the random fraction during fitting. Since we only observed such an increase in the isotropic emission yield but no narrowing of channeling profiles, we conclude that for the higher doses most Er atoms are also located on near$\mathrm{T}$ sites, and dechanneling is mainly responsible for decreasing the visible fraction..

Upon annealing at $600^{\circ} \mathrm{C}$ the $\mathrm{Si}$ lattice is restored to a large extent, which shows up as a pronounced increase in the visible near-T fraction of all crystals. Before drawing further conclusions, we have to remark that the site fractions can only be determined with a precision around $10 \%$, which is also the reason for occasional fractions above $100 \%$. This results from the fact that even for a perfect crystal there are three major sources of error. First, the implantation depth profile in a single crystal is not precisely known. Although our samples were produced by implanting at $7^{\circ}$ from the surface normal, there always exist channeling tails. Secondly, dechanneling of electrons by thermal scattering from lattice atoms and crystal electrons is only approximated in our simulations through perturbation theory. Thirdly, the measured electron yield has to be corrected for electrons which are backscattered from the bulk of the sample. This is done by subtracting a trapezoidal background from every electron line in the energy spectrum. Keeping these limits on the accuracy in mind, we conclude that up to $700^{\circ} \mathrm{C}$ there are no obvious differences between $\mathrm{FZ}$ and CZ Si samples implanted with the same doses. The furnace-annealed samples tend to lie at smaller near-T fractions. This can be explained since they did not receive the full $10 \mathrm{~min}$ treatment at the respective temperatures.

At higher annealing temperatures, however, especially at $900^{\circ} \mathrm{C}$, pronounced differences between CZ Si and FZ Si are evident. While the near-T fractions in CZ Si decrease rapidly for isothermal annealing at $900^{\circ} \mathrm{C}$ [Fig. 2(d)], only prolonged annealing of the order of hours is able to reduce them in FZ material [Fig. 2(c)]. A close view to the results in CZ Si shows that the rate of decrease is anti-correlated with the implanted dose, i.e. the stability on near-T sites is higher for samples implanted with a higher dose of $(\mathrm{Tm}+\mathrm{Er})$. In FZ the trend seems to be reversed, i.e. the stability is highest in the sample with the lowest $(\mathrm{Tm}+\mathrm{Er})$ dose.

A possible reason for the vanishing channeling effects is the incorporation of Tm and Er into disordered regions, e.g. precipitates which are of random orientation with respect to the rest of the lattice or even amorphous. Adopting this hypothesis, the fact that the stability of near-T Er in $\mathrm{CZ} \mathrm{Si} \mathrm{decreases} \mathrm{with} \mathrm{increasing} \mathrm{O} / \mathrm{Er}$ ratio indicates that $\mathrm{O}$ catalyzes the formation of the precipitates or is a major constituent of them. Note that in $\mathrm{CZ} \mathrm{Si} \mathrm{we} \mathrm{have} \mathrm{O} /(\mathrm{Tm}+\mathrm{Er})$ ratios above 0.04-0.4 for the low-dose and 0.004-0.04 for the high-dose implanted samples, but more $\mathrm{O}$ can be supplied by the bulk of the crystal. In FZ Si, on the other hand, the incorporation of Er in disordered regions occurs much slower but seems to be faster for higher Er concentrations. Here $\mathrm{O} /(\mathrm{Tm}+\mathrm{Er})$ ratios are a factor of 10-100 smaller. The most simple explanation, which in particular also accounts for the dose dependence in both $\mathrm{CZ}$ and $\mathrm{FZ} \mathrm{Si}$, is that in $\mathrm{CZ} \mathrm{Si}$ we have formed, e.g., disordered $(\mathrm{Tm} / \mathrm{Er})_{2} \mathrm{O}_{3}$-like precipitates, while in $\mathrm{FZ} \mathrm{Si}$ they are, e.g., $(\mathrm{Tm} / \mathrm{Er}) \mathrm{Si}_{2}$-like.

\section{CONCLUSIONS}

The results of our as-implanted lattice location experiments have provided additional evidence that isolated $\mathrm{Er}$ in Si occupies near-tetrahedral interstitial sites. However, we can not exclude the fact that these sites are influenced by defects resulting from the implantation process. Annealing of $\mathrm{Tm} /$ Er-implanted samples at $900^{\circ} \mathrm{C}$ leads to pronounced structural changes, possibly incorporation of $\mathrm{Tm} / \mathrm{Er}$ into disordered precipitates. In CZ Si this occurs fastest in samples implanted with low doses of $\mathrm{Tm} / \mathrm{Er}$, while in FZ it is fastest for high-dose implanted samples. We 
conclude that the increase in luminescence efficiency, which is usually observed for Er-implanted $\mathrm{CZ}$ or $\mathrm{O}$ co-implanted $\mathrm{Si}$ following annealing at $900^{\circ} \mathrm{C}$, is accompanied by the formation of disordered precipitates. However, since more than $90 \%$ of $\mathrm{Er}$ is optically inactive $[8,9]$ and therefore invisible to PL, these precipitates need not necessarily be responsible for the enhanced Er luminescence.

\section{ACKNOWLEDGEMENTS}

We are grateful to H. Hofsäss for the permission to use his electron channeling simulation code "MANYBEAM". J.G.C. acknowledges his post-doc grant funded by JNICT, Portugal, and A.V. by the post-doctoral research program of the Fund for Scientific Research, Flanders (FWO).

\section{REFERENCES}

[1] M. Needels, M. Schlüter and M. Lannoo, Phys. Rev. B 47, 15533 (1993).

[2] F. Gan, L.V.C. Assali and L.C. Kimerling, Materials Science Forum, 196-201, 579 (1995).

[3] H. Ennen, G. Pomrenke, A. Axmann, K. Eisele, W. Haydl and J. Schneider, Appl. Phys. Lett. 46, 381 (1985).

[4] S. Libertino, S. Coffa, G. Franzó and F. Priolo, J. Appl. Phys. 78, 3867 (1995).

[5] D.J. Eaglesham, J. Michel, E.A. Fitzgerald, D.C. Jacobson, J.M. Poate, J.L. Benton, A. Polman, Y.H. Xie and L.C. Kimerling, Appl. Phys. Lett. 58, 2797 (1991).

[6] F. Y. G. Ren, J. Michel, Q. Sun-Paduano, B. Zheng, H. Kitagawa, D. C. Jacobson, J. M. Poate and L. C. Kimerling, Mat. Res. Soc. Proc. 301, 87 (1993).

[7] H. Przybylinska, W. Jantsch, Y. Suprun-Belevitch, M. Stephikhova, L. Palmetshofer, G. Hendorfer, A. Kozanecki, R. J. Wilson and B. J. Sealy, Phys. Rev. B 54, 2532 (1996).

[8] A. Polman, J. Appl. Phys. 82, 1 (1997).

[9] J. Michel, F.Y.G. Ren, B. Zheng, D.C. Jacobson, J.M. Poate and L.C. Kimerling, Materials Science Forum, 134-147, 707 (1994).

[10] D.L. Adler, D.C. Jacobson, D.J. Eaglesham, M.A. Marcus, J.L. Benton, J.M. Poate and P.H. Citrin, Appl. Phys. Lett. 61, 2181 (1993).

[11] A. Terrasi, G. Franzo, S. Coffa, F. Priolo, F. D'Acapito and S. Mobilio, Appl. Phys. Lett. 70, 1712 (1997).

[12] K. Nakashima, O. Eryu, O. Iioka, T. Nakata and M. Watanabe, Nucl. Instr. Meth. B 127, 475 (1997).

[13] U. Wahl, A. Vantomme, J. De Wachter, R. Moons, G. Langouche, J.G. Marques, J.G. Correia, and the ISOLDE collaboration, Phys. Rev. Lett. 79, 2069 (1997).

[14] U. Wahl, J.G. Correia, J. De Wachter, G. Langouche, J.G. Marques, R. Moons, A. Vantomme, and the ISOLDE collaboration, Mat. Res. Soc. Proc. 469 (1997) in print.

[15] U. Wahl, J.G. Correia, G. Langouche, J.G. Marques, A. Vantomme, and the ISOLDE collaboration, presented at the the International Conference on Defects in Semiconductors, Aveiro, 22.-25.7.97. See also CERN preprint PPE 97-139.

[16] U. Wahl, J.G. Correia, S. Cardoso, J.G. Marques, A. Vantomme, G. Langouche, and the ISOLDE collaboration, presented at the $13^{\text {th }}$ International Conference on Ion Beam Analysis Lisbon, 27.7.-1.8.97, accepted for publication in Nucl. Instr. Meth. B.

[17] P. Weilhammer, E. Nygård, W. Dulinski, A. Czermak, F. Djama, S. Gadomski, S. Roe, A. Rudge, F. Schopper and J. Strobel, Nucl. Instr. Meth. A 383, 89 (1996). 